\title{
The effect of virtual reality glasses on anxiety during surgery under spinal anesthesia: a randomized controlled study
}

\author{
Ayse Z Turan ${ }^{1}$, Mehmet Yilmaz ${ }^{1} \bowtie$, Tolga Saracoglu ${ }^{2}$ \\ Authors' affiliations: \\ 1- Consultant, Department of Anesthesia, Health and Science University, Derince Training and Research Hospital, Kocaeli, 41900, \\ Turkey. \\ 2- Associate Professor, Department of Anesthesia, Health and Science University, Kartal Dr. Lutfi Kirdar Education And Research \\ Hospital,Istanbul, 34865, Turkey. \\ Correspondence: Dr. Ayse Zeynep Turan, Ibni Sina Mah, Lojman Sok, Derince Eğitim Araştırma Hastanesi, Derince/ Kocaeli, Turkey; E-mail: \\ ayse.zeynep@gmail.com; Phone: +902623178000
}

\section{Abstract}

Background \& objectives: Surgery-related anxiety can be observed due to several factors in patients undergoing surgery. With developing technology virtual reality (VR) glasses have begun to be used to reduce anxiety in the preoperative period. We aimed to investigate the effect of using VR glasses on operation anxiety and sedation requirement in patients during operation under spinal anesthesia.

Methodology: We enrolled 97 patients between 18-75 y of age, ASA class I-II, in this study. Participants were randomized into VR glasses group or the standard care group. The State-Trait Anxiety Inventory for Trait Anxiety (STAI-TA) and State-Trait Anxiety Inventory for State Anxiety (STAI-SA) scores preoperatively and anxiety score on VAS scale during surgery were obtained. Patients watched a movie via VR glasses (BOBO ${ }^{\circledR}$ VR Z4) after spinal anesthesia and the surgical operation was commenced thereafter. In the control group, the surgery was begun without any additional procedure.

Results: Both groups were similar in terms of demographic and hemodynamic data. There was no statistically significant difference between groups in terms of preoperative anxiety levels, STAI-SA and STAI-TA scores. However, the VAS and relative risk (RR) values were significantly lower in the study group in all measurements $(p<0.05)$.

Conclusion: We believe that the use of VR glasses decreases perioperative anxiety and sedation requirements in patients undergoing a surgical procedure under spinal anesthesia.

Key words: Spinal Anesthesia; Virtual Reality; Anxiety; Sedation

Citation: Turan AZ, Yilmaz M, Saracoglu T. The effect of virtual reality glasses on anxiety during surgery under spinal anesthesia: a randomized controlled study. Anaesth pain intensive care 2021;25(2):170-175. DOI: 10.35975/apic.v25i2.1469

Received: 31 January 2021, Reviewed: 22, 25 February 2021, Accepted: 27 February 2021

\section{Introduction}

Perioperative anxiety begins in the preoperative period and may continue in the postoperative period. It results due to several factors in patients undergoing surgery. ${ }^{1-}$
${ }^{3}$ Although it varies in different groups of patients, the frequency in adult patients has been reported to be between $11 \%$ and $90 \% .^{2,4-6}$ Anesthesia-related anxiety is another cause of perioperative anxiety, and it may be due to intraoperative awareness, fear of pain during 
intervention, postoperative pain, nausea and vomiting. ${ }^{3}$

Perioperative anxiety leads to difficult intravascular access, need for increased anesthesia depth, hypertension, dysrhythmias, pain, nausea, vomiting, increased risk of infection, and prolonged recovery period. ${ }^{7-9}$ Therefore, it is important to be aware of and to treat the perioperative anxiety. ${ }^{10,11}$ Various tests have been developed to determine anxiety levels of the patients. ${ }^{3}$

Recently virtual reality (VR) applications have been introduced. By this way, it is possible to be included in the virtual environment, both visually and auditory. ${ }^{12,13}$ Due to this feature, virtual reality glasses (VRG) have begun to be used to reduce anxiety in the preoperative period. ${ }^{4}$ VRG have been used to reduce preoperative anxiety in several studies. However, there is a limited number of studies that eveluate efficacy of VR on intraoperative anxiety. ${ }^{12,13}$

In this study, we investigated the effect of using VRG on perioperative anxiety and the requirement of sedation during surgery in patients under spinal anesthesia.

\section{Research Methodology}

We conducted the study after approval of the local Ethics Committee Protocol No: 2017/226, and registered with Clinicaltrials.gov: NCT03475810. The study was conducted between September 2017 and January 2018 in our operating theatres.

The study included surgical patients between the ages of 18-75 years, with an American Society of Anesthesiologists (ASA) class I-II, scheduled to undergo surgery under spinal anesthesia in the supine position. All patients gave their written informed consent to participate. Patients with psychiatric disorders, undergoing emergency surgeries or cesarean section, patients with visual impairment and those who could not speak, read or write in our language, were excluded from the study.
The participants were randomized into two groups; those using VRG (study group) and the standard care group (control group) with the closed envelope method.

The preoperative State-Trait Anxiety Inventory for Trait Anxiety (STAI-TA) and State-Trait Anxiety Inventory for State Anxiety (STAI-SA) scores were determined for all patients to evaluate their anxiety status in the preoperative preparation unit. ${ }^{14,15}$ The visual analogous scale (VAS-A) was used to evaluate the anxiety level during surgery. ${ }^{16}$. For this purpose, patients were asked to rate their anxiety between 0 (no anxiety at all) band 10 (the most severe anxiety in my life) on a scale.

Premedication was not allowed to the patients before surgery. Electrocardiography (ECG) recording, peripheral oxygen saturation $\left(\mathrm{SpO}_{2}\right)$ and non-invasive blood pressure monitoring was applied to all participants in the operating theatre. After insertion of the 20-gauge intravenous cannula, $500 \mathrm{ml}$ of $0.9 \%$ saline was administered at a rate of $10 \mathrm{ml} / \mathrm{kg} / \mathrm{h}$. An anesthesiologist, who was blind to the patients' group, performed spinal anesthesia using a 26-gauge pencilpoint needle (Spineject®). Heavy Marcaine was administered to the subarachnoid space and the drug dose was adjusted according to the surgery the patient would undergo.

Spinal anesthesia was considered satisfactory for all patients with a Bromage score of 2-3 points and a negative pinprick test. Patients watched a nature documentary which was specially prepared for VR

\begin{tabular}{|c|c|c|c|c|}
\hline \multicolumn{2}{|c|}{ Variables } & $\begin{array}{l}\text { Control Group } \\
(n=47)\end{array}$ & $\begin{array}{l}\text { VR Group } \\
(n=50)\end{array}$ & p-value \\
\hline \multirow[t]{2}{*}{ Gender } & Female & 5 & 12 & \multirow[t]{2}{*}{$0.079^{k}$} \\
\hline & Male & 42 & 38 & \\
\hline \multicolumn{2}{|l|}{ Age $(y)$} & $41 \pm 32$ & $44,5 \pm 24$ & $0.346^{m}$ \\
\hline \multirow{2}{*}{$\begin{array}{l}\text { ASA } \\
\text { Class }\end{array}$} & ASA 1 & 18 & 21 & \multirow[t]{2}{*}{$0.710^{k}$} \\
\hline & ASA 2 & 29 & 29 & \\
\hline \multicolumn{2}{|c|}{$\begin{array}{l}\text { Number of attemption for } \\
\text { spinal anesthesia }\end{array}$} & $1 \pm 0$ & $1 \pm 0,25$ & $0.398 \mathrm{~m}$ \\
\hline \multicolumn{2}{|c|}{ Duration of operation (min) } & $45 \pm 33$ & $45 \pm 30$ & $0.902^{m}$ \\
\hline \multicolumn{5}{|c|}{${ }^{k}$ Ki-kare test: values are given as frequency (percentage) } \\
\hline
\end{tabular}


technology via VRG (BOBO® VR Z4) after spinal anesthesia and the surgical operation was commenced thereafter (Figure 1). In the control group, the surgery was commenced.

During the surgery, systolic arterial pressure (SAP), diastolic arterial pressure (DAP), heart rate (HR), $\mathrm{SpO}_{2}$, respiratory rate (RR) and VAS anxiety scoring were evaluated every ten minutes. A VAS anxiety score of 0 to 3 points was considered as mild anxiety, and a score of 4 points or higher was accepted as moderate-severe anxiety and these patients received $0.03 \mathrm{mg} / \mathrm{kg}$ benzodiazepine and $1 \mu \mathrm{g} / \mathrm{kg}$ fentanyl for required in each group to determine the difference in terms of anxiety parameters between the study groups. The sample size of our study was sufficient and our study had high reliability.

\section{Results}

A total of 97 patients between $18-75 \mathrm{y}$ of age $(43.8 \pm$ $16.41 \mathrm{y})$ were included in the study; $17(17.5 \%)$ of them were female and $80(82.5 \%)$ were male. Patients who had been scheduled for spinal anesthesia, but switched to general anesthesia due to a failed block sedation.

\section{Statistical Analysis:}

Statistical analysis of the data was carried out using the IBM SPSS Statistics 22. In the analysis of the numerical data, the Independent Samples $t$ Test was used for those conformed to the normal distribution, the MannWhitney $\mathrm{U}$ test for those who did not, the chisquared test was used for the analysis of categorical variables, the one-way ANOVA test and the Kruskal-Wallis $\mathrm{H}$ test were used for the comparison of more than 2 groups. The bivariate correlation test was used in the relationship analysis of independent variables. The MINITAB program was used in the power analysis. The results were evaluated within the $95 \%$ confidence interval and a $p<0.05$ was accepted as statistically significant.

Assuming a bilateral $\alpha$ with a $95 \%$ confidence interval and $80 \%$ power, we calculated that 47 participants would be

\begin{tabular}{|c|c|c|c|}
\hline Anxiety tests & $\begin{array}{l}\text { Control Group } \\
(n=47)\end{array}$ & $\begin{array}{l}\text { VR Group } \\
(n=50)\end{array}$ & p-value \\
\hline Preoperative STAI-SA & $42 \pm 10$ & $44 \pm 10$ & $0.353^{m}$ \\
\hline Preoperative STAI-TA & $47.49 \pm 7.17$ & $48.6 \pm 6.7$ & $0.432^{s}$ \\
\hline \multicolumn{4}{|c|}{$\begin{array}{l}\text { STAI-SA: The Stait Trait Anxiety Inventory-State Anxiety Scale, } \\
\text { STAI-TA: The Stait Trait Anxiety Inventory-Trait Anxiety }\end{array}$} \\
\hline
\end{tabular}

\begin{tabular}{|c|c|c|c|}
\hline Parameter & $\begin{array}{l}\text { Control Group } \\
(n=47)\end{array}$ & $\begin{array}{l}\text { VR Group } \\
(n=50)\end{array}$ & p-value \\
\hline $\mathrm{SAP}(\mathrm{mmHg})$ & $129.6 \pm 20.97$ & $127.54 \pm 18.84$ & $0.609 \mathrm{~s}$ \\
\hline $\mathrm{DAP}(\mathrm{mmHg})$ & $73.09 \pm 14.09$ & $73.08 \pm 11.89$ & $0.996 \mathrm{~s}$ \\
\hline HR (beat/min) & $74.86 \pm 13.56$ & $77.93 \pm 13.87$ & $0.274 \mathrm{~s}$ \\
\hline $\mathrm{SpO}_{2}(\%)$ & $98.6 \pm 2$ & $98.6 \pm 1.75$ & $0.758 \mathrm{~m}$ \\
\hline $\mathrm{RR}(/ \mathrm{min})$ & $14 \pm 2.4$ & $13.2 \pm 1.25$ & $0.002^{m}$ \\
\hline VAS & $5.19 \pm 1.64$ & $4.1 \pm 1.91$ & $0.003^{s}$ \\
\hline \multicolumn{4}{|c|}{$\begin{array}{l}\text { SAP: Systolic arterial pressure, DAP:Diastolic arterial pressure, HR:heart rate,SpO2: Periphera } \\
\text { oxygen saturation, RR:respiratory rate, VAS: anxiety score on visual analog scale } \\
\text { m Mann-Whitney U test: values are given as mean } \pm \text { standard deviation (median+lqr) } \\
\text { s independent Samples } t \text { test: values are given as mean } \pm \text { standard deviation }\end{array}$} \\
\hline
\end{tabular}

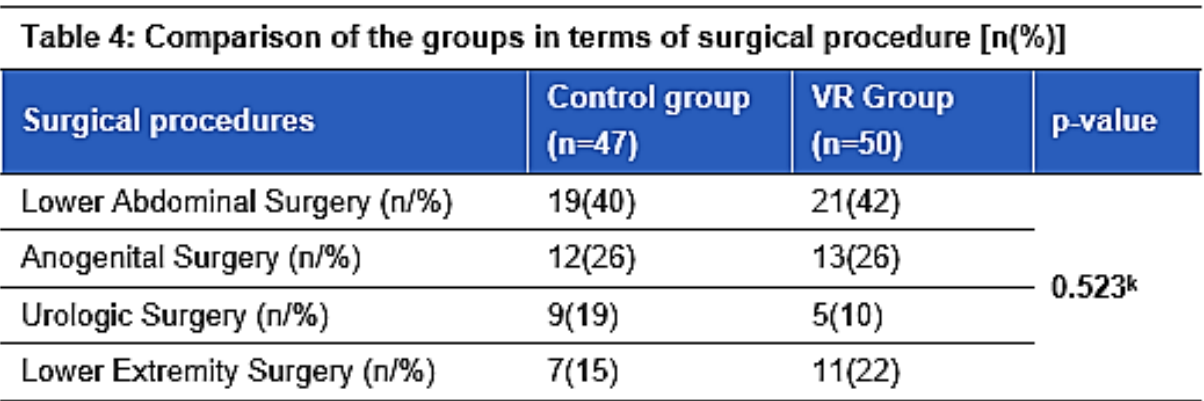

${ }^{k} \mathrm{~K}$-kare test: values are given as frequency (percentage) 
$(n=9)$ and patients with missing data $(n=3)$ were excluded from the study (flow chart).

There were 50 patients in the study group and 47 in the control group. Both groups were similar in terms of demographic data (Table 1). There was no statistically significant difference between groups in terms of preoperative anxiety levels, STAI SA and STAI TA scores (Table 2).

According to the comparison of vital parameters during surgery, there was no statistically significant difference between groups in terms of SAP, DAP, HR and $\mathrm{SpO}_{2}$ values ( $\left.\mathrm{p}>0.05\right)$. However, the VAS and RR values were significantly lower in the study group in all measurements $(\mathrm{p}<0.059)$ (Table 3$)$.

The incidence of past surgical history was significantly lower in the study group as compared to the control group; 18 vs. 32 patients $(p=0.001)$. We compared the sedation administration rates of the groups and we found that sedation was rarely performed in the study group compared to the patients in the control group [13 vs. 27 respectively $(\mathrm{p}=$ 0.002)].

We did not find a significant correlation between the sedation administration and previous surgical history ( $\mathrm{p}=0.81$ ). Similarly, there was no significant correlation between perioperative VAS anxiety score and previous surgical history $(\mathrm{p}=0.781)$. There was no significant difference between groups in terms of types of surgery (Table 4).

\section{Discussion}

In this prospective randomized controlled study, we investigated the effect of using VRG on patient anxiety and sedation requirement during surgeries performed under spinal anesthesia. We determined that the use of VRG reduces the patient anxiety and the need for sedation.

Several factors play role in development of surgical anxiety. The most important ones are the prolonged waiting period for surgery, fears about the possible harm and consequences of the operation, separation from family members, expecting pain and the risk of complications. $^{4}$ Some studies have reported that smoking, female gender, ASA score, the presence of psychiatric disorders and cancer history are linked to the higher levels of surgical anxiety. ${ }^{5}$ We interpreted this situation as the reason for surgery-related anxiety being affected by many factors and that standardization of the studies on this subject was almost impossible.

In our study, we used the state anxiety scale (STAISA) and the continuity anxiety scale (STAI-TA) to evaluate the anxiety level of participants. While the STAI-TA shows the anxious personality structure, the STAI-SA scale evaluates the instant anxiety level of the subject. It has been stated that there is a relationship between surgery-related anxiety and high anxious personality. ${ }^{6-7}$ In our study, the continuity anxiety scale and the condition anxiety scale of the study groups were similar.

Studies reported that surgery-related anxiety is higher in women than in men. ${ }^{5,8,9}$ On the other hand, several studies stated that there is no difference between the genders in surgery-related anxiety. ${ }^{9,10,11}$ In our study, the female gender anxiety scales in the study group were similar to the male gender. We interpreted this situation as the female gender did not affect the results in our study. Several previous studies reported that surgery-related anxiety decreases with the increase in patient age. ${ }^{14,15}$ In our study, the groups were similar in terms of patient age. We interpreted this situation as the age did not affect the results in our study.

Surgery-related anxiety is caused by many factors such as surgery and anesthesia type. ${ }^{11,16}$ It has been reported that informing patients about surgery and anesthesia in the preoperative period may have a positive effect on anxiety. ${ }^{11,17}$ All patients in our study were informed verbally and in written form regarding surgery and anesthesia in the preoperative period.

Some authors reported that patients who have undergone surgery previously have less surgical anxiety. ${ }^{18,19}$ However, other authors differed from this opinion. ${ }^{3}$ In our study, we did not find a significant correlation between previous surgical history and anxiety levels and the need for sedation. We interpreted that patients can experience the surgery even they did no underwent surgery before, via multimedia tools All kinds of written and/or visual information about the surgical operation are available electronically. Patients can now access detailed information about any operation, whenever they wish. In this way, patients can obtain information in detail, 
despite having no experience in the relevant issue previously.

According to the comparison of anxiety scores of the patients undergoing regional anesthesia and general anesthesia, the anxiety scores of patients in the regional anesthesia group were lower. ${ }^{16}$ The awareness of the patient during regional anesthesia being open to visual stimuli has an increasing effect on the perioperative anxiety level. ${ }^{20}$ It is a common clinical practice to administer sedative agents to reduce perioperative anxiety in the vast majority of patients undergoing an operation under spinal anesthesia. There are very few studies using alternative treatment methods to provide perioperative anxiety control in patients undergoing regional anesthesia. In a study conducted to test the effect of music listening during the operation in patients under regional anesthesia, it was reported that listening music was effective in reducing perioperative anxiety. ${ }^{21}$ Similarly, in another study, it was reported that visual stimuli could be used in reducing perioperative anxiety; however, the visual stimulation used in this study was the visual therapy applied in the preoperative period. ${ }^{22}$

Virtual reality technologies have begun to be used frequently in the treatment of anxiety disorder in clinical psychiatry. ${ }^{23-25}$ Besides, virtual reality technologies have been used to reduce anxiety in the preoperative period in patients undergoing a surgical procedure. ${ }^{4}$ Its effectiveness has also been shown in controlling pain and anxiety on patients undergoing surgical and dental procedures in the operating room. ${ }^{4}$ In all of these studies, virtual reality technologies were applied in the preoperative period before the surgical procedure. The difference between our study and previous studies is that we applied the VRG during the surgical procedure in patients undergoing spinal anesthesia. Our study revealed that VRG could reduce the perioperative anxiety, and consequently the need for drugs used for sedation. It may be as a result of limiting their exposure to visual stimuli by using VRG in patients operated under spinal anesthesia.

\section{Limitations}

The most important limitation of our study was that there were many concurrent factors on perioperative anxiety that we could not standardize and measure. These factors include religious belief, educational level, waiting period for surgery, the marital status and the previous experience of the patient regarding surgery and anesthesia.

\section{Conclusion}

In conclusion, we believe that the use of virtual reality glasses during the surgery decreases perioperative anxiety and accordingly the need for sedation in patients undergoing a surgical procedure under spinal anesthesia. We are in the opinion that, further largescale, multicenter, prospective studies are needed to further establish the usefulness of this modality.

\section{Conflict of interest}

None declared by the authors.

\section{Authors' contribution}

AZT: Content of work, study design, data collection, manuscript writing, statistical analysis

MY: Data Collection, Statistical Analysis, Critical Revision

KTS: Critical Revision, Study Design, Statistical Analysis

\section{References}

1. Goebel S, Kaup L, Mehdorn HM. Measuring preoperative anxiety in patients with intracranial tumors. J Neurosurg Anesthesiol. 2011;23:297-303. [PubMed] DOI: $10.1097 / A N A .0 b 013 e 318222 b 787$

2. Perks A, Chakravarti S, Manninen P. Preoperative anxiety in neurosurgical patients. J Neurosurg Anesthesiol. 2009;21:127-130. [PubMed] DOI: 10.1097/ANA.0b013e31819a6ca3

3. Buonanno P, Laiola A, Palumbo C, Spinelli G, Terminiello V, Servillo G. Italian validation of the Amsterdam preoperative anxiety and information scale. Minerva Anestesiol. 2017;83(7):705-11. [PubMed] DOI: 10.23736/S0375-9393.16.11675-X

4. Caumo W, Schmidt AP, Schneıder CN, Bergmann J, Iwamoto $\mathrm{CW}$, Banderra $\mathrm{D}$, et al. Risk factors for preoperative anxiety in adults. Acta Anaesthesiol Scand. 2001 Mar;45(3):298-307. [PubMed] DOI: 10.1034//.1399-6576.2001.045003298.x

5. Yilmaz M, Sezer H, Gưrler H, Bekar M. Predictors of preoperative anxiety in surgical inpatients. J Clin Nurs. 2011.;21(7-8):956-964. [PubMed] DOI: 10.1111/j.1365-2702.2011.03799.x

6. Carr E, Brockbank K, Allen S, Strike P. Patterns and frequency of anxiety in women undergoing gynaecological surgery. J Clin Nurs. 2006;15:341-352. 
[PubMed] DOI: 10.1111/j.1365-2702.2006.01285.x

7. Norred C. Minimizing preoperative anxiety with alternative caring-healing therapies. AORN J. 2000;72:838-843. [PubMed] DOI: 10.1016/s00012092(06)62015-2

8. Shuldham C. A review of the impact of pre-operative education on recovery from surgery. Int J Nurs Stud. 1999;36:171-177. [PubMed] DOI: 10.1016/s00207489(99)00010-3

9. Mavridou P, Dimitriou V, Manataki A, Arnaoutoglou E, Papadopoulos G. Patient's anxiety and fear of anesthesia: effect of gender, age, education, and previous experience of anesthesia. A survey of 400 patients. J Anesth. 2013;27(1):104-8. [PubMed] DOI: 10.1007/s00540-012-1460-0

10. Ebirim L, Tobin M. Factors responsible for preoperative anxiety in elective surgical patients at a university teaching hospital: a pilot study. Internet J Anesthesiol. 2010;29:2. [FreeFullText]

11. Kiyohara LY, Kayano LK, Oliveira LM, Yamamoto MU, Inagaki MM, Ogawa NY, et al. Surgery information reduces anxiety in the pre-operative period. Rev Hosp Clin Fac Med Sao Paulo. 2004 Apr;59(2):51-6. [PubMed] DOI: $10.1590 / \mathrm{s} 0041-87812004000200001$

12. Wiederhold MD, Gao K, Wiederhold BK. Clinical use of virtual reality distraction system to reduce anxiety and pain in dental procedures. Cyberpsychol Behav Soc Netw. 2014 Jun;17(6):359-65. [PubMed] DOI: 10.1089/cyber.2014.0203

13. Walker MR, Kallingal GJ, Musser JE, Folen R, Stetz MC, Clark JY. Treatment efficacy of virtual reality distraction in the reduction of pain and anxiety during cystoscopy. Mil Med. 2014 Aug;179(8):891-6. [PubMed] DOI: $10.7205 / M I L M E D-D-13-00343$

14. Taşdemir, A., Erakgün, A., Deniz, M. N., \& Çertuğ, A. Comparison of preoperative and postoperative anxiety levels with state-trait anxiety Inventory test in preoperatively informed patients. Turk J Anaesthesiol Reanim. 2013;41:44-49. DOI: 10.5152/TJAR.2013.11

15. Aykent R, Kocamanoglu l', Ustün E, Tür A, Sahinoglu H. The reasons and evaluation of preoperative anxiety: a comparison of APAIS and STAI scores. Turkiye Klinikleri J Anesth Reanim. 2007;5(1):7. [FreeFullText]
16. Jlala HA, French JL, Foxall GL, Hardman JG, Bedforth NM. Effect of pre- operative multimedia information on perioperative anxiety in patients undergoing procedures under regional anaesthesia. $\mathrm{Br} J$ Anaesth. 2010;104(3):369-74. [PubMed] DOI: 10.1093/bja/aeq002

17. Mitchell M. Influence of gender and anaesthesia type on day surgery anxiety. J Adv Nurs. 2011;68(5):10141025. [PubMed] DOI: 10.1111/j.13652648.2011.05801.x

18. Caumo W, Schmidt AP, Schneider CN, Bergmann J, Iwamoto CW, Bandeira D, et al. Risk factors for preoperative anxiety in adults. Acta Anaesthesiol Scand. 2001;45(3):298-307. [PubMed] DOI: 10.1034/j.1399-6576.2001.045003298.x

19. Badner NH, Nielson WR, Munk S, Kwiatkowska C, Gelb AW. Preoperative anxiety: detection and contributing factors. Can J Anaesth. 1990;37(4):444-7. [PubMed] DOI: $10.1007 / \mathrm{BF} 03005624$

20. Fredrikson M, Fischer H, Wik G. Cerebral blood flow during anxiety provocation. J Clin Psychiatry. 1997;58 Suppl 16:16-21. [PubMed]

21. Koç H, Erk G, Apaydın Y, Horasanlı E, Yiğitbaşı B, Dikmen B. Epidural Anestezi ile Herni Operasyonu Uygulanan Hastalarda Klasik Türk Müziğinin Intraoperatif Sedasyon Üzerine Etkileri. Turk J Anesth Reanim. 2009;37(6).

22. Norred $\mathrm{CL}$. Minimizing preoperative anxiety with alternative caring-healing therapies. AORN J. 2000 Nov;72(5):838-40, 842-3. [PubMed] DOI: 10.1016/s0001-2092(06)62015-2

23. Walkom $\mathrm{G}$. Virtual reality exposure therapy: to benefit those who stutter and treat social anxiety. International conference on Interactive technologies and games. IEEE. 2016; 36-41. DOI: 10.1109/iTAG.2016.13

24. Gorini A, Riva G. Virtual reality in anxiety disorders: the past and the future. Expert Rev Neurother. 2008 Feb;8(2):215-33. [PubMed] DOI: $\underline{10.1586 / 14737175.8 .2 .215}$

25. Maples-Keller JL, Bunnell BE, Kim SJ, Rothbaum BO. The Use of Virtual Reality Technology in the Treatment of Anxiety and Other Psychiatric Disorders. Harv Rev Psychiatry. 2017 May/Jun;25(3):103-113. [PubMed] DOI: $10.1097 / H R P .0000000000000138$ 